\title{
UBUNTU AND CAPABILITIES APPROACH: BASIC DOCTRINES FOR CALIBRATING HUMANITARIAN ACTION
}

\author{
Mashele RAPATSA \\ Faculty of Management and Law, University of Limpopo, South Africa. \\ LLB (UL) LLM (UCT) PhD student, University of Groningen, the Netherlands. \\ (C) 2016 Mashele RAPATSA \\ This is an open access article distributed under the Creative Commons Attribution-NonCommercial-NoDerivs license \\ (http://creativecommons.org/licenses/by-nc-nd/3.0/) \\ DOI: $10.1515 /$ eras-2016-0002
}

\begin{abstract}
This article explores prospects of using Ubuntu and Capabilities Approach to expand the scope of humanitarian action, to design one which serves humanity better even in the absence of disaster to essentially fulfil human development needs. It is considerate of the fact that humanitarian works contributes immensely in determining the extent to which humanity thrives. The traditional view on humanitarianism presupposes action-driven initiatives geared towards devising interventions to restore or reinforce human social order, improve livelihoods and quality of life. In sociological terms, human development is dependent on realizing and safeguarding, amongst others, human well-being, civil liberties and social security. The article utilizes core values enshrined in Ubuntu, Africa's historic philosophy of life, and Amartya Sen's Capabilities Approach as tools of analysis, with the view to expressing how to operationalize what should be considered stable humanitarian conditions and human well-being. Owing to persistent socio-economic challenges, especially the poverty problem, it is asserted that humanitarian action ought to depart from being a post-disaster intervention strategy, to being a pro-active and preventative pre-disaster orientated action, intended to nurture well-being and resultantly enable human development.
\end{abstract}

Keywords: humanitarianism, human well-being, human capabilities, poverty, Ubuntu.

\section{Introduction}

Even in the absence of human-induced disasters and/or natural disasters, humanitarian needs shall remain a permanent commodity (Lucchi, 2012:58), without which humanity is most likely to experience social turbulences. Thus, this article provides an exposition of ostensibly neglected area of humanitarianism and humanitarian action, an attempt to stimulate the humanitarian community to change course and re-imagine how they perceive and approach humanitarian crisis and humanitarian needs. It is indisputable that humanitarianism as a way of life and its humanitarian agencies play a very important role in the sustenance of humanity. It is for this reason that there is widespread consensus that humanitarian action find its essential motivation in the principle of humanity, which has been defined by the International Federation of Red Cross and Red Crescent Societies (IFRC) as 'the desire to prevent and alleviate human suffering wherever it may occur... to secure life and health, and to ensure respect for the human being' (Hilhorst \& Schmiemann, 2002:491).

By extension, core elements of serving humanity would include, striving to provide basic necessities for the survival of humans as a matter of non-negotiable urgency. It also encompasses expressing compassion, caring, love and creating an environment where people are capacitated to exercise basic capabilities and achieve functionings in a fully-fledged way. Given this rich meaning of humanity, the fundamental question to ask, as humanitarians, 
would be predicated on whether our actions indeed pursue similar objectives of humanity or are actions inclined to furthering political agendas or self-centred political interests? This is crucial because contemporary humanitarian action often is crisis driven, which may alternatively be characterized as being a post-disaster intervention mechanism. Somewhat, this approach is considered contentious, necessarily because human beings in many parts of the world are faced with life threatening phenomena owing to socio-economic deprivations that render their humanitarian conditions squalid. This refers to regions that have not experienced neither natural nor man-made disasters, yet their humanitarian conditions are not improving because of poverty and diseases for instance. And these poor socio-economic conditions often play part in breeding human-induced violence, conflicts and humanitarian crises. Thus, what ought to be the primary focus of humanitarian action in principle? Arguably, it has to advance humanitarianism, which can best be described as an attitudinal phenomenon whose triumph is contingent on how humans interact and treat each other.

This humanitarian action constantly revives hope to the world community, especially among indigent communities inhabiting under-developed or developing regions of the world. This refers particularly to regions where social strife, poverty, inequalities, lack of opportunities and low literacy levels are common phenomena. It is for this reason that every so often, one imagines the extent to which the distinct but interdependent concepts of humanitarian action and human development could be utilized to execute seamless works of humanitarians. That is to say, what frameworks can we develop to make humanitarian agencies function better to fulfil human development aspirations? And in what ways should this be pursued, and to achieve what?

Perhaps I should begin by stressing my allegiance to traditional humanitarian imperatives founded on serving humanity better. But I am critical of how scholars across spectrums of political, social, legal and anthropological sciences, and humanitarians such as Non-Governmental Organizations and other private actors perceive of humanitarian action in the modern world.

\section{Humanitarian action and its international principles}

Ordinarily, humanitarian action is constituted by acts of advancing humanitarianism and/or humanitarian welfare. It is centred on creating interventions that restores acceptable human order, by inducing enabling circumstances that fosters uninterrupted continuation of life filled with dignity, harmony and sustainable human development. This humanitarianism suggests that human life and dignity are essentially valuable and should be protected irrespective of gender, race, tribe, religious or political affiliation (Macrae, 1998:309). In that regard, any act which seeks to safeguard human life and avert human suffering will thus qualify as humanitarian action. Medics refer to this as an act of reducing morbidity and mortality (Tong, 2003:181). However, prevailing international perspectives have problematically restricted the meaning of humanitarian action to two instances, that is, as an act of intervening in times when human life is threatened or is in misery due to disasters ensuing from human-induced wars or natural phenomena such as floods, earthquakes, tornado thunders and so forth. Such a framework is considered problematic because, is humanity better served only in times of man-made disasters and/or natural disasters? I argue that humanitarianism is not a circumstantial phenomenon which has to depend on events. Instead, more work could be done even in times of peace and without natural disasters to make people realize quality life and happiness, thereby preventing possible conflicts that create humanitarian crises.

Indisputably worth mentioning is that central to this project is the idea of preventing or 
alleviating human suffering and/or death, but in conformity to specific principles built upon international humanitarian law (Burges, 2002:262; Morris, 2008:25).These humanitarian principles provide ethical framework and foundation that guide humanitarian action in situations of conflict and complex emergencies. The principles of humanity, impartiality, independence and neutrality assist humanitarians to navigate in various political, security and physical challenges when seeking safe access to people in need of assistance and protection.

This article focuses on the principle of humanity, a prime humanitarian principle which has profound resonance with the human rights theory (Fox, 2001:275; MacFarlene \& Weiss, 2000:112), Ubuntu principle and Capabilities Approach. Humanity principle also plays a crucial role in socializing humans and determining how they live and interact with each other. According to Slim (2005:5), the humanity principle is predicated on a popular slogan of "life with dignity", which entails that it is not enough to only keep humans alive. Instead, it implores humanitarians to concede the urgency of fostering efforts of achieving high quality of life, which should not only arise in the form of post-disaster immediate rescue operation. This entails that the humanity principle dissuades interventions that only come in response to war or natural disasters. A clear convergent of the humanity principle with human rights doctrines, which ironically only gained momentum during early nineteen-nineties (Hilhorst \& Jansen, 2012:897), is evident in the fact that humanity prioritizes respect and protection of human dignity. Even though some rights are more basic than others, like imminent threat to life either resulting from socio-economic deprivations or from direct violation of civil rights, all rights are fundamental as a means to dignity (Pease \& Forsythe, 1993:308). Thus, dignity in terms of the rights language is seen as a foundational norm, the yardstick in the interpretation and understanding of human rights (Rapatsa, 2015) and humanitarian action, especially socio-economic rights that are largely human welfare focused. The rights and humanitarian partnership is also premised on the fact that from our common humanity derives shared ethics of universality and equality (Darcy, 2004:8), norms which have widely been communicated through rights-based approaches.

\section{Rationale and methodology}

The object of this article is to explore prospects of departing from a post-disaster humanitarian action, especially with regards to pervasive human-induced crises that come subsequent to wars, government failures, tribal and religious conflicts. It is considerate of the fact that human-induced disasters can be averted through pro-active preventative approaches. Hence, the article proposes a rather pro-active interventionist humanitarian approach which focuses on addressing factors that lead to conflict, particularly in instances where such conflicts are given impetus by socio-economic deprivations. Because of notable expansion of humanitarian action, which has stretched from being a simple thought of saving lives into recognizing the importance of securing livelihoods (Buchanan-Smith \& Cosgrave, 2013:13), this work advances an argument that authentic humanitarian work should be premised on addressing socio-economic deprivations such as on aspects of abject poverty, malnourishment, health care, shelter and access to education in a manner that enables humans to achieve freedoms that help them determine what they want to do or to be. Once these material conditions are altered for the better, humanitarians and the world community can meaningfully secure livelihoods and thus sustainable human development.

This article derives from the principle of 'humanity', which is part and parcel of the international principles on humanitarian action. It seeks to inspire thoughts and add another dimension to humanitarian action, a move which emphasizes that pre-disaster intervention action is an appropriate way to avert human-induced crises. This is aimed at inculcating 
methods that reinforces efforts of securing livelihoods to fulfil the traditional essence of humanitarianism. I attempt to respond to these research questions; first, is it possible to calibrate the focus of humanitarian action? Second, how can we foster a progressive expansion of the scope of humanitarian action? Third, how significant can values enshrined in Ubuntu and Capabilities Approach (CA)be in furtherance of such a goal? This work relies heavily on moral and philosophical basis founded in Ubuntu and CA to respond to these questions. This derives from the fact that people who live in abject poverty are more vulnerable, and often docile, to humanitarian crises.

The article adopts a qualitative style of research. It uses content analysis method relying on primary and secondary sources including statutes and other legal instruments, books, reports and journal articles. It explores the power of core values founded by Ubuntu and CA towards securing livelihoods.

\section{Theoretical framework}

To acquire and retain legitimacy in the eyes of the public, activities of humanitarian agencies need to be backed by strong ethical, normative, moral and philosophical connotations that are people centred, life sensitive, and also give due regard to human entitlements expressed through the human rights theory. This entails that humanitarians ought to act only in furtherance of protecting human interests, especially those embedded in the being of humans. In this regard, it is significant to conceive appropriate theories which offer dogmas that can be relied upon. This article hinges on the principle of Ubuntu and Capabilities Approach, theories that promise to play as panaceas in filling noticeable pitfalls playing out within the humanitarian community.

The power of Ubuntu can be obtained by borrowing from South Africa's experience, which is time and again exemplified through the country's transition from apartheid to egalitarian dispensation. This principle, which resonates with universal values of human worth and dignity (Eliastam, 2015:2) paved the way for transformative society thereby fostering social cohesion, creating an environment in which humans value the importance of achieving substantive social justice and equality. It requires all people to be ethical human beings that protect one another (Mkhize, 2008:35). The theoretical strengths of Ubuntu have been reflected in a variety of ways. Notably, this is inclusive of Ubuntu being formulated as a constitutional value that became operationalized in law (Tshoose, 2009:16), with Mokgoro (1998:20) arguing that the values of Ubuntu became an integral part of the normative value system engrained in the country's Constitutional Supremacy system of governance. This system carried with it, the burden of defining how people would interact and treat each other.

In an attempt to substantiate the magnitude of the power and strong appeal of Ubuntu as an ethical and moral theory, Eliastam(2015:2) enumerated ways that enunciates how it has been embodied. He states that Ubuntu serves as a foundation of moral theory, as the basis for public policy, as a normative value for education and business ethics, as the bedrock for African approach to conflict resolution and peace building, as a guiding principle for citizenship education, as the framework for a theology of religious ontology, and in the main, Ubuntu cultivated strong philosophical basis for constitutional democracy. In addition, Ubuntu inculcates a culture of responsible citizenship, thereby creating mutual reciprocity of trust between state and individuals, and amongst private entities and individuals.

Ubuntuis embraced as a philosophy of life in many parts of African nations. Its origins can be traced to Africa's humanist philosophy which pursues common humanity that thrives on the basis of advancing and protecting people's commonalities. It means 'humanness', that 
'umuntungumuntungabantu' or 'mothokemothokabatho', which means, literally 'a person is a person through others persons'. It is traditionally based on the conception that 'I am a person because you are; that I cannot separate my humanity from acknowledging your humanity' (Sachs, 2012), which Tshoose (2009) argued is a way of encouraging group solidarity. Nussbaum (2003:21) posited Ubuntu as a social value upon which humanitarianism derives its prime strength. She argued that Ubuntu augments the idea of providing humanitarian needs, where well-being of humans, free from strife and conflict is a priority. According to Nussbaum, ideals of Ubuntu have greater potential to contribute immensely in moulding world consciousness as far as humanitarian work is concerned.

Ubuntu articulates social interdependence and a profound community-based interactive ethic where our humanity is shaped by our interactions as co-dependent beings (Letseka, 2012:57). Kamwangamalu (1999:27) presents Ubuntuas a value in terms of which interest of individual is subordinate to that of the group/community, a pan-African concept which symbolizes the core values of African ontologies which includes respect for humans, human dignity, the need for humility, interdependence and communalism, and augment social solidarity. According to Murithi (2007:287), the wisdom of Ubuntu lies in the recognition that it is impossible to build a healthy community at peace with itself unless every member of the community has their human dignity respected and protected.

The logical and ultimate expression of Ubuntu is to secure freedom and respect for all humanity, with the goal of achieving stable humanitarian conditions for all (Nussbaum, 2003:24). It is therefore amenable to operate on assumptions that the primacy of Ubuntu on humanitarian action is inherently founded. It protects interests and rights of humans as individuals and as communities, and it is expressive of humanitarian objectives in totality. Then, what contributions can be deduced from Capabilities Approach?

Moral approaches that assist in determining what is indispensable for human survival are essential doctrines that inform formulation of social policy and humanitarian activities. One such a tool is Amartya Sen's Capabilities Approach. Here, fundamental moral and philosophical basis of $\mathrm{CA}$ are shown, thereafter extrapolating its usefulness towards humanitarianism and how it could guide humanitarian agencies. Sen coined CA in the nineteen-eighties which would later become popular as a tool of evaluating human well-being. Since then, what has been dominating his works is the promotion of human well-being and human development (Clark, 2005:1340).He states that the primary feature of a person's wellbeing is the functioning vector that he/she achieves, which takes into account how a person can function (Sen, 1985:197). This well-being leads to a certain concept of freedom, that is, it gives humans the ability to decide what they want to do or to be. It can be argued that humanitarian actors, while executing their functions, should similarly pursue this goal.

According to Sen, factors that determine well-being are activities that a person is able to engage in (capacity to do e.g. eating, seeing, reading, walking etc) or state of existence or being (which is concerned with being well nourished, being healthy, and most importantly being free from poverty or abject poverty). Sen uses the language of human capabilities to emphasize that humanitarian conditions in a given setting are central to determining adequate opportunities for humans to survive. He described capabilities as a set of vectors of functionings, reflecting the person's freedom to lead one type of life or another... to choose from possible livings (Sen, 1992:40). This freedom influences one's functionings, things a person may value doing and achieving (Sen, 1999:75). Sen also indicated that CA and human rights have common motivation premised on protecting humans from risks that may expose them to suffering (Sen, 2005:152). Its core theme boils on an appeal to safeguard humanity.

Deducible from CA is that it embraces a humanist stance, offering alternative discourse to contemporary instrumental practices(Wright, 2012:421) including such activities 
of humanitarian agencies. What CA does is that it builds a strong synergy between rightsbased approaches and humanitarian action, by emphasizing that we should enable human beings to attain basic necessities of life in order for their lives to be on par with satisfactory humanitarian standards.

\section{Calibrating humanitarian works to move beyond the confines of 'disaster': discussion}

The importance of humanitarian action is centred on providing relief, thereby mitigating negative impacts of crises on a people. But it appears that in regard to humaninduced crises, post disaster-based intervention strategy runs short of fulfilling the entire mission of humanitarianism, necessarily because very often than not, it does not offer permanent solutions to crises ridden environments. Commonly it only provides a temporary relief without uprooting circumstances or factors that generate discontent, violence and eventual crisis. Thus, it needs to be complimented by a pre-emptive approach which is preventative in form. For instance, to move beyond the confines of 'disaster', we have to appreciate that the sub-standard living conditions where almost every dweller suffers as a result of chronic systems failures and dire health hazards is the tipping point for humanitarian crisis (Zetter \& Deikun, 2010:6), and therefore act accordingly to uplift the standard of living. This is particularly crucial for private humanitarian organisations, especially because they have been playing a critical role as primary implementing agencies in conflict ridden areas, and at times, being forces giving impetus to international humanitarian law in practice (Frangonikolopoulos, 2005:49; Stoddard, 2009:25).

I should reiterate that it is not my intention to rewrite the meaning of humanitarian action, but if this work unwittingly does that, such a burden is well accepted. In actual fact, this work is more of an appeal to humanitarians to consider expanding the scope to cover instances where notwithstanding such absence of either of noted disasters, human life is under siege. By subjecting humanitarian action to Ubuntu and Capabilities Approach, what useful lessons can be obtained to improve our work as humanitarians? Most importantly, from Ubuntu and CA, humanitarians can end up having an almost homogenised system of humanitarianism which embraces shared values, even though the international principles may not be seen as being sacrosanct and/or static given global social and economic diversities.

What is clear is that keywords that feature predominantly in humanitarian work revolves around prevention and/or alleviation of human suffering, prevention of loss of life, restoration of social order and civilians' uninterrupted life. Ubuntu encourages communities and individuals alike, to always work together, show compassion and prevent conflicts for the collective good of society. In a way, it preaches prevention is better than cure, with the view that human-induced humanitarian crises can be avoided. On the other hand, CA preaches that we should strive to create an environment that protects people's freedom to choose what activities to participate in with the desire to better their well-being. Which is that, capabilities are central in determining what functionings people can achieve.

\section{Conclusion}

This article intended to put forward the idea of exploring prospects of expanding scope of humanitarian action, with the view to enhancing our understanding and application of humanitarianism. It resonate the view that for humanitarians to deal effectively with pressing humanitarian problems, some amount of modification is indispensable. In its present form, humanitarian action is disaster-based, and come in the form of social interventions or civil and socio-economic relief. The system is vulnerable to abuse by predatory actors who may lose 
their impartiality and neutrality while fighting for legitimacy, thus compromising the principle of humanity. It is shown that the principle of humanity shares commonalities with moral strengths founded in Ubuntu and Capabilities Approach, doctrines which offers dependable normative guidelines that can be applied to design a complimentary pre-disaster proactive humanitarianism. It is asserted that relying on Ubuntu and Capabilities Approach may result in homogenised systems, which will most likely improve effectiveness and accountability in humanitarian interventions. Moving forward, this work proposes a reconsideration of the meaning of humanitarian crisis. This is necessary because once there is widespread consensus, new terms regarding scope and focus of humanitarian action may develop, guided significantly by strengths evidenced in the principle of humanity, reinforced by theoretical and philosophical connotations derived from Ubuntu and CA.

\section{References}

Buchanan-Smith, M. \& Cosgrave, J. (2013). Evaluation of Humanitarian Action: Pilot Guide. The Active Learning Network for Accountability and Performance in Humanitarian Action (ALNAP), London: Overseas Development Institute.

Burges, J.P. (2002). Ethics of Humanitarian Intervention: The Circle Closes. Security Dialogue, 33(3), $261-264$.

Clark, D.A. (2005). Sen's capability approach and the many spaces of human well-being. The Journal of Development Studies, 41(8), 1339-1368.

Darcy, J. (2004). Human Rights and Humanitarian Action: A review of the issues. Humanitarian Policy Group (HPG) Background Paper. London: Overseas Development Group.

Eliastam, J.L.B. (2015). Exploring Ubuntu discourse in South Africa: Loss, liminality and hope. Verbum et Ecclesia, 36(2), 1-8.

Fox, F. (2001). New Humanitarianism: Does It Provide a Moral Banner for the $21^{\text {st }}$ Century? Disasters, 25(4), 275-289.

Frangonikolopoulos, C.A. (2005). Non-governmental Organisations and Humanitarian Action: The Need for a Viable Change of Praxis and Ethos. Global Society, 19(1), 49-72.

Hilhorst, D. \&Schmiemann, N. (2002). Humanitarian principles and organisational culture: Everyday practice in Meedecins Sans Frontie res-Holland. Development in Practice, 12(3-4), 490-500.

Hilhorst, D. \& Jansen, B. (2012). Constructing Rights and Wrongs in Humanitarian Action: Contributions from a Sociology of Praxis. Sociology, 46(5), 891-905.

Kamwangamalu, N.M. (1999). Ubuntu in South Africa: a Sociolinguistic Perspective to a Pan-African Concept. Critical Arts: South-North Cultural and Media Studies, 13(2), 24-41.

Letseka, M. (2012).In Defence of Ubuntu. Studies in Philosophy Education, 31, 47-60.

Lucchi, E. (2012). Moving from the 'why' to the 'how': reflections on humanitarian response in urban settings. Disasters, 36(1), 87-104.

MacFarlene, S.N. \& Weiss, T. (2000). Political Interest and Humanitarian Action. Security Studies, 10(1), $112-$ 142.

Macrae, J. (1998). The Death of Humanitarianism: An Anatomy of the Attack. Disasters, 22(4), 309-317.

Mkhize, N. (2008). Ubuntu and harmony: An African approach to morality and ethics. In Nicholson, R. (ed.) Persons in community: African ethics in a global culture, pp.35-44. Scottsville: UKZN Press.

Mokgoro, Y. (1998). Ubuntu and the Law in South Africa. Potchefstroom Electronic Journal, 1(1), 15-26.

Morris, N. (2008). The Evolution of Humanitarian Action. Refugee Survey Quarterly, 27(1), 24-29.

Murithi, T. (2007). A local response to the global human rights standards: the Ubuntu perspective on human dignity. Globalisation, Societies and Education, 5(3), 277-286.

Nussbaum, B. (2003). Ubuntu: Reflections of a South African on Common Humanity. Reflections, 4(4), 21-26.

Pease, K.K. \& Forsythe, D.P. (1993). Human Rights, Humanitarian Intervention, and World Politics. Human Rights Quarterly, 15(2), 290-314.

Rapatsa, M. (2015). Human Dignity as a Foundational Norm in the Understanding of Human Rights. Bangladesh e-Journal of Sociology, 12(2), 41-53.

Sachs, A. (2012). Liberty, Equality, Fraternity: Bringing Human Solidarity Back Into the Rights Education. Journal of Human Rights Practice, 4(3), 365-383.

Sen, A.K. (1985). Well-being, Agency and Freedom: The Dewey Lectures 1984. The Journal of Philosophy, 82(4), 169-221.

Sen, A.K. (1992). Inequality Re-examined. Oxford: Clarendon Press.

Sen, A.K. (1999). Development as Freedom. New York: Alfred A. Knopf, Inc. 
Sen, A.K. (2005). Human Rights and Capabilities. Journal of Human Development, 6(2), 151-166.

Slim, H. (2005). Idealism and Realism in Humanitarian Action. Two Talks Given at the ACFID Humanitarian Forum, Canberra, 5 October 2005. Centre for Humanitarian Dialogue.

Stoddard, A. (2009). Humanitarian NGOs: challenges and trends. In Joanna, M. \& Adele, H., Humanitarian Action and the 'Global War on Terror': A Review of Trends and Issues, (eds.). pp.25-36, HPG Report, HPG: London.

Tong, J. (2003). Questionable Accountability: MSF and Sphere in 2003. Disasters, 28(2), 176-189.

Tshoose, C.I. (2009). The Emerging Role of the Constitutional Value of Ubuntu for Informal Social Security in South Africa. African Journal of Legal Studies, 3(1), 12-19.

Wright, H.R. (2012). Child care, children and capability. Cambridge Journal of Education, 42(3), 409-424.

Zetter, R. \& Deikun, G. (2010). Meeting humanitarian challenges in urban areas. Forced Migrant Review, 34(5), 5-7. 